\title{
ASSESSMENT OF ABNORMALLY LOW TENDERS: A MULTINOMIAL LOGISTIC REGRESSION APPROACH
}

\author{
Murat GUNDUZ ${ }^{\mathrm{a}}$, H. Volkan KARACAN ${ }^{\mathrm{b}}$ \\ ${ }^{a}$ Department of Civil Engineering, Qatar University, P.O. Box: 2713 Doha, Qatar \\ ${ }^{b}$ Civil Engineer, GENA Ltd., Ankara, Turkey
}

Received 04 February 2014; accepted 09 November 2014

\begin{abstract}
This study was performed in order to reveal factors affecting abnormally low tenders (ALTs) and to minimize negative effects of them. A thorough literature review was carried out to observe past research about the reasons of and possible solutions to ALTs. A questionnaire was prepared and submitted to construction professionals to capture negative impacts of ALTs based on the interviews with experts and past literature. 430 companies responded to the questionnaire. The data analysis was carried out by the multinomial logistic regression statistical tool. Having quality control systems and restricted procedure with prequalification procurement systems were main significant factors to reduce ALTs. Based on all significant factors, recommendations were made to construction professionals and companies to reduce adverse effects of ALTs.
\end{abstract}

Keywords: abnormally low tenders, inquisition rates, multinomial logistic analysis.

JEL Classification: C83, H57, L74.

\section{Introduction}

The essence of the tender is making advanced productivity through the market competition mechanism so as to effectively promote economic development and social progress (Jun 2013). However, one of the major problems in procurement in construction industry is abnormally low tenders (ALTs). Pricing decisions are fundamental in developing a marketing strategy (Coskun et al. 2013). Contracting authorities are hesitant to award a tender to the lowest bid as they doubt whether it is also the most advantageous compared to other bids.

The purpose of this paper is to assess the factors affecting ALT in public construction works and capture reasons and factors behind the problem. To achieve this goal, firstly, a literature review was carried out. Then, a questionnaire was developed and administered to construction professionals. 430 construction companies responded to the questionnaire.

Corresponding author Murat Gunduz

E-mail: mgunduz@qu.edu.qa 
Finally, multinomial logistic regression was used to capture factors affecting ALT inquisition rate and to make recommendations to the construction industry.

\section{Factors leading to abnormally low tenders}

Contractor evaluation is a vital part of the project management cycle and deals with risk and risk management. One of the most important phases in the construction industry is the bidding process (Turskis 2008). The competitive bidding system has been to blame for abnormally low bids, which are considered as one of the main causes of poor project quality (Lo et al. 2007). The low-bid method, typically used for competitive bidding in the United States, may result in a contract with a firm that submits either accidentally or deliberately an unrealistically low-bid price (Ioannou, Awwad 2010). Many governmental institutions and researchers try to capture the factors leading to abnormally low tenders.

Banaitiene and Banaitis (2006) stated that only on the basis of quantitative and qualitative evaluation criteria and by comparing bids of contractors it is possible to select a qualified, competent and reliable contractor, to evaluate its qualification, economic and financial condition and technical capability and skills and to achieve relevant results in a construction project.

According to Calveras et al. (2003), the reasons of abnormally low tenders were expectation of renegotiating the contract later on when it would be costly for sponsor to replace the existing company, taking a risky strategy for survival of a company which was in a bad financial state and protection of firms which went through bankruptcy by limited liability (bankruptcy laws).

In EU, some of the reasons for accepting ALT were insufficient risk analysis, lack of resources or skills, inadequate selection criteria, justification of contract awards and limited scope of EU directives (Harrower 1999).

Harrower (1999) mentioned that public entities did not operate on the basis of private risk capital so they could submit tenders far below the costs of private enterprise. Moreover, constrained financial situation of public authorities resulted in award of contracts to the lowest bidder but the problem was that they did not think of additional costs like deficient quality of work and supervision of work.

As the reasons for awarding the bid to the lowest price, Unuvar (2004) listed insufficiency of risk analyses, lack of confidence among contracting authorities in their own conceptual cost and the anxiety of protecting interests of the government treasury.

Current study tries to capture the reasons behind the abnormally low tenders with the help of a questionnaire and analysis of the collected data through statistical means.

\section{Literature review on ALTs}

Literature review on past ALT researches was carried out to have insight about ALTs and their possible solutions.

Lo et al. (2007) mentioned that the competitive bidding system has been to blame for abnormally low bids, which are considered as one of the main causes of poor project 
quality. They adapted system dynamics to develop a contractor's pricing model with consideration of the dimensions of cost, market competition and beyond-contractual reward (BCR). The model was then examined by statistical analysis of data collected from 44 highway projects in Taiwan. It was found that the equilibrium market price is significantly associated with BCR, which is assumed to be determined by the strictness of the owner's construction management, including both soundness of contract and tightness in construction supervision.

Gokce (2004) talked about the inquiry procedure of abnormally low tenders. According to the author, when the contracting authority was not sure about its own conceptual estimate, it awarded the abnormally low tender as the winner. Another reason of awarding the lowest bidder was the benefit of treasury.

EU issued a directive 2004/18/EC. This directive is about public supply, public works and public services. The general definition of ALTs, necessity of written explanations and their conditions are given in that directive.

Directorate General III published a report about abnormally low tenders. Causes for submitting ALTs and accepting ALTs, recommendations for preventing and eliminating abnormally low tenders were mentioned in that report. Economically most advantageous tender (EMAT) system was recommended to the client with this report (Harrower 1999).

The most important issues in auction design are the traditional concerns of competition policy-preventing collusive, predatory, and entry-deterring behaviour. Ascending and uniform-price auctions are particularly vulnerable to these problems (Klemperer 2002). Detecting abnormally low bids in procurement auctions is a recognized problem, since their acceptance could result in the winner not being able to provide the service or work awarded by the auction, which is a significant risk for the auctioneer (Conti et al. 2012). In their study, a rank-and-compare algorithm is considered to detect such anomalous bids and help auctioneers in achieving an effective rejection decision. Analytical expressions and simulation results are provided for the detection probability, as well as for the false alarm probability.

In Drew and Skitmore (1997), multiple regression was used to construct a prediction equation relating bidder competitiveness (the dependent variable) to the independent variables of bidder, contract type and contract size. The regression model showed that differences in contractor competitiveness are greater for different contract sizes than for different contract types. The most competitive contractors appeared to be those with a preferred contract size range. Such a model can be used as part of a more systematic approach in prequalifying contractors. It may also be used by contractors as a basis for assessing bidding performance.

Six different identification strategies were tested empirically by application, both independently and in pooled form, to several sets of auction data gathered from around the world by Skitmore (2002). The results indicate the normal density to be the most appropriate model and a multiple of the auction standard deviation to be the best identification strategy.

Ballesteros et al. (2013) presented a new test for detecting abnormally high or low bids among those who enter a tender, and taking advantage of the data, any tender analyst or 
person in charge of supervising capped tenders will be able to suspect which bidders are involved in a cartel after identifying the same abnormal behaviour in a series of tenders by means of a simple method.

Lo and Yan (2009) stated that abnormally low bids and contractors' opportunistic bidding behaviour are frequently observed in the competitive bidding system. Many research findings have pointed out that price competition itself is not sufficient to guarantee the use of economical and good quality products. Their paper developed a simulation model to analyse contractors' pricing behaviour and dynamic competition process under the qualification-based selection (QBS) system.

Bergman, Lundberg (2013) compared theoretical results with actual procurements, as reflected in a sample of 189 Swedish public procurements of four services: elderly care, waste transport, food wholesale services and cleaning services. They found that the lowest price is used in more than one-third of the procurements while supplier selection based on scoring rules that include both price and quality measures are used in more than half of the procurements. They also argued that quality-to-price scoring outperforms price-toquality scoring.

Six different identification strategies were tested empirically by application, both independently and in pooled form, to eight sets of auction data gathered from around the world by Skitmore, Lo (2002). The results indicate the most conservative identification strategy to be a multiple of the auction standard deviation assuming a lognormal composite density. Surprisingly, the normal density alternative was the second most conservative solution.

Yu, Wang (2012) proposed an index named price elasticity of performance (PEP) that may serve as a quantitative measure to reach an objective decision. The theoretical model construction of PEP was also described. Two measures in the individual and market levels of PEP were defined. A design/build construction project was selected as a working example to demonstrate the applicability of the proposed method. Potential applications and limitations of the proposed method are also addressed. It was concluded that the proposed PEP method has the potential to resolve the dilemma of pursuing efficiency and avoiding violation of regulations in traditional procurements.

By using cluster analysis, five groups of bidders with distinctive bid profiles were identified and the associated bid markups were calculated by Hartono, Yap (2011). The emerging groups provide an empirical illustration on how the theoretical model is utilized. The theoretically grounded framework could be used by contractors to improve their own bidding strategy in anticipating the likely behaviour of the competitors.

Threshold tests were applied to identify common and unique categories and an absolute difference test to determine the principal categories of criteria used in the evaluation of tenders by Watt et al. (2009). The study, using a pragmatic and heuristic approach, resulted in the identification of eight principal categories suitable for our research program.

Conti, Naldi (2008) mentioned that procurement auctions may be affected by abnormally low bids, whose acceptance may have negative consequences on the auctioneer. A method, based on the average submitted bid, was considered to detect such anomalous bids and aid the auctioneer in the possible rejection decision. Analytical expressions or simulation results were provided for the detection probability and for the false alarm probability. 
A total of 670 hours of work observed in both firms revealed three stages of the bidding process by Laryea, Hughes (2011). Their findings explain why some assumptions underpinning analytical models may not be sustainable in practice and why what actually happens in practice is important for those who seek to model the pricing of construction bids.

Alexandersson, Hultén (2006) studied the bidding behaviour of firms participating in public tenders of passenger railway services in Sweden. They discussed the various possible reasons behind high and low bids in tenders, linked to a discussion on pricing strategies and continuous and discontinuous economies of scale regarding costs of production.

\section{Methodology}

For this study, ALT evaluation was carried out by using a questionnaire form. The questionnaire had eighteen questions. Confidentiality was assured to the respondents. The questionnaire was arranged after the literature review process with the help of experts in this area.

The questionnaire was distributed as hardcopies in the first run. Consequently, a webpage was developed and most of the responses were collected through that webpage. The webpage questionnaire was linked in parallel to other webpages to increase the number of responses. The questionnaire can be seen in Table 1 .

Table 1. Abnormally low tender questionnaire

\begin{tabular}{|c|c|}
\hline ALT questionnaire questions & Type of data collected \\
\hline $\begin{array}{l}\text { How many people are working at central office in your } \\
\text { company? }\end{array}$ & — \\
\hline Which type of works do you deal with? & Infrastructure, Power Plants etc. \\
\hline Does your company work abroad? & Yes or No \\
\hline $\begin{array}{l}\text { How do you determine prices of each work item on bid } \\
\text { package? }\end{array}$ & Multiple Choice \\
\hline Which factor affects your final bid price at most? & Risk, Regular Payment etc. \\
\hline $\begin{array}{l}\text { If a bid was determined as the lowest tender, what are the } \\
\text { reasons of it? }\end{array}$ & Multiple Choice \\
\hline How often do you face abnormally low tender inquisition? & $0-25 \%, 26-50 \%, 51-75 \%, 76-100 \%$ \\
\hline How many tenders do you bid in a year? & _ \\
\hline Do you use computer software for tender price calculation? & $\overline{\text { Yes or No }}$ \\
\hline $\begin{array}{l}\text { Which can be documented regarding originality of work } \\
\text { and advantageous conditions in ALT inquisition? }\end{array}$ & Multiple Choice \\
\hline $\begin{array}{l}\text { Please scale materials/works according to advantageous } \\
\text { conditions. } \\
\text { (1 - most important, } 14 \text { - least important) }\end{array}$ & Workmanship, Cement, Steel etc. \\
\hline $\begin{array}{l}\text { Do you think that not adapting to Public Procurement Law } \\
\text { causes abnormally low tenders? }\end{array}$ & Yes or No \\
\hline $\begin{array}{l}\text { Do you think that proper and sufficient quality control is } \\
\text { applied especially in construction period? }\end{array}$ & Yes, Generally, Sometimes, No \\
\hline $\begin{array}{l}\text { Is restricted procedure with prequalification appropriate for } \\
\text { solving abnormally low tenders? }\end{array}$ & Yes or No \\
\hline $\begin{array}{l}\text { Please indicate average percentage values for bid types you } \\
\text { participate in a year? }\end{array}$ & Lump-sum,Restricted, Negotiated \\
\hline $\begin{array}{l}\text { Is surety bond system appropriate for solving abnormally low } \\
\text { tenders? }\end{array}$ & Yes, No, Not applicable \\
\hline How can abnormally low tender problem be solved? & \\
\hline
\end{tabular}




\section{Data characteristics}

Four hundred and thirty companies filled out the questionnaire. The companies were also clustered as small, medium and large companies depending on the number of employees. The companies were grouped according to their sizes as small (1-5 employees), medium (6-25 employees) or large companies ( $>25$ employees). The total number of small, medium and large companies was 247, 138 and 39 respectively. The data was collected in Turkey. The distribution of amount of work types according to size of companies can be seen in Table 2. Amount of work types is the total number of types the respondent works on from the following fields: Infrastructure (1), Power plants (2), Mechanical plumbing (3), Telecommunication (4), Railways, Airports, Seaports (5), Pipe line, Fuel plants (6), Superstructure (7), Electric works (8). Superstructure and infrastructure were the major types of work.

Table 2. Distribution of amount of work types according to size of companies

\begin{tabular}{ccccccc}
\hline & \multicolumn{3}{c}{ Size of companies } & \multicolumn{3}{c}{ Size of companies } \\
\hline $\begin{array}{c}\text { Amount of } \\
\text { work types }\end{array}$ & $\begin{array}{c}\text { Small } \\
\text { companies }\end{array}$ & $\begin{array}{c}\text { Medium } \\
\text { companies }\end{array}$ & $\begin{array}{c}\text { Large } \\
\text { companies }\end{array}$ & $\begin{array}{c}\text { Small } \\
\text { companies }\end{array}$ & $\begin{array}{c}\text { Medium } \\
\text { companies }\end{array}$ & $\begin{array}{c}\text { Large } \\
\text { companies }\end{array}$ \\
\hline 1 & 131 & 72 & 20 & $53 \%$ & $52 \%$ & $51 \%$ \\
\hline 2 & 74 & 36 & 5 & $30 \%$ & $26 \%$ & $13 \%$ \\
\hline 3 & 23 & 10 & 5 & $9 \%$ & $7 \%$ & $13 \%$ \\
\hline No answer & 7 & 12 & 8 & $5 \%$ & $9 \%$ & $20 \%$ \\
\hline Total & 247 & 8 & 1 & $3 \%$ & $6 \%$ & $3 \%$ \\
\hline
\end{tabular}

Most companies specified the bid price through market research. Additional price estimation means were cost analysis of similar works and unit prices.

The response rate in this study is high and noteworthy, because the industry professionals wanted to solve this issue in all ways.

In the questionnaire the respondents were asked how often they face abnormally low tender inquisition. Moreover, they were asked to rate the reasons for the ALTs. Table 3 shows the reasons of ALTs considering size of companies due to ALT Inquisition Rates from the data collected. ALT Inquisition means that if the proposed tender is below a threshold value determined by some formula, the tender will go through a screening process by the tendering agency. ALT Inquisition rate counts for how often the contract faces the screening process.

The methods of determining prices are shown in Table 4. It can be easily seen that prices are usually determined by market research.

\section{Multinomial logistic regression of ALTs}

Logistic regression is a model used for prediction of the probability of occurrence of an event. It makes use of several predictor variables that may be either numerical or categories (Agresti 2002). Logistic regression has 3 types of models. One of the types of models is 
Table 3. Reasons of ALTs considering size of companies due to ALT inquisition rate

\begin{tabular}{|c|c|c|}
\hline \multicolumn{3}{|c|}{$\begin{array}{l}\text { Reasons of ALTs due to ALT inquisition rate of 0-25\% } \\
\text { Size of companies }\end{array}$} \\
\hline Small & Medium & Large \\
\hline 1. Staying in business & Miscalculation of bid price & Work experience document \\
\hline 2. Miscalculation of bid price & Staying in business & Miscalculation of bid price \\
\hline 3. Work experience document & Work experience document & Inaccuracy of conceptual cost \\
\hline \multicolumn{3}{|c|}{ Reasons of ALTs due to ALT inquisition rate of $26-50 \%$} \\
\hline Small & Medium & Large \\
\hline 1. Staying in business & Staying in business & Miscalculation of bid price \\
\hline 2. Miscalculation of bid price & Miscalculation of bid price & Work experience document \\
\hline 3. Inaccuracy of conceptual cost & Inaccuracy of conceptual cost & Staying in business \\
\hline \multicolumn{3}{|c|}{ Reasons of ALTs due to ALT inquisition rate of $51-75 \%$} \\
\hline Small & Medium & Large \\
\hline 1. Staying in business & Staying in business & Staying in business \\
\hline 2. Miscalculation of bid price & Inaccuracy of concep. cost & Work experience document \\
\hline 3. Inaccuracy of conceptual cost & Miscalculation of bid price & Advantageous conditions \\
\hline \multicolumn{3}{|c|}{ Reasons of ALTs due to ALT inquisition rate of $76-100 \%$} \\
\hline Small & Medium & Large \\
\hline 1. Staying in business & Miscalculation of bid price & Staying in business \\
\hline 2. Miscalculation of bid price & Staying in business & Inaccuracy of conceptual cost \\
\hline 3. Inaccuracy of conceptual cost & Advantageous conditions & Work experience document \\
\hline
\end{tabular}

Table 4. Methods of determining prices of work items

\begin{tabular}{lccc}
\hline & Small companies & Medium companies & Large companies \\
\hline Market research & $46 \%$ & $45 \%$ & $44 \%$ \\
\hline Unit prices & $25 \%$ & $22 \%$ & $20 \%$ \\
\hline Determining most appropriate price & $12 \%$ & $15 \%$ & $15 \%$ \\
\hline Cost analysis of similar works & $17 \%$ & $18 \%$ & $21 \%$ \\
\hline
\end{tabular}

multinomial logistic regression. This type of regression is used when data of response have categorical variables more than two. In this study, the response data was chosen as ALT Inquisition rate. It has 4 variables, which are $0-25 \%, 26-50 \%, 51-75 \%, 76-100 \%$ Inquisition rates. SPSS software was used for the statistical analysis. Inquisition rates were coded by numbers from 1 to 4 respectively to increasing rates of inquisition from $0-25 \%$ to $76-100 \%$.

Logistic regression has some assumptions (Garson 2014) but it does not require all the assumptions of normal regression. Response (dependent) variable should be coded meaningfully. Generally positive sign coding is used. Error terms are assumed to be independent. Logistic regression does not require linearity between independent factors and dependent variables. Moreover, there should be no multicollinearity in the model. Large samples should be used because logistic regression uses maximum likelihood estimation. Large samples should be used so that there will be low standard errors. These assumptions were satisfied with the proposed statistical model. 
The odds ratio (Agresti 2002) is a measure of effect important in logistic regression. In multinomial logistic regression, estimates of independent variables are found by using relative reference category. In other words, odds ratio shows relative importance of variable to the reference category.

where: $P(y)$ : Probability of occurrence.

$$
\begin{gathered}
\text { Odds ratio }=\exp (B)=\frac{\text { Odds }(\text { event })}{\text { Odds }(\text { other event })} ; \\
\text { Odds }=\frac{P(y)}{1-P(y)},
\end{gathered}
$$

The reference category for dependent variable was chosen as 0-25\% ALT Inquisition Rate. The reference category for independent variables was last the category which SPSS software automatically selected them. Qualitative data were coded numerically for entry to the software. Multicollinearity variables were found by using Spearman two-tailed correlation. Elimination was carried out by considering least correspondence to the dependent variable. After the elimination process, standardized residuals were found and they were excluded from the model. However, in multinomial regression, SPSS does not calculate standardized residuals directly. So, residuals were first calculated by using difference of actual and estimated response category. Then, standard deviation and mean of residuals were found. Finally standardized residuals (SR) were found by using SPSS and values more than 1.96 values were excluded according to equation 3 .

$$
S R=\frac{\text { Residual }-\bar{x}}{s},
$$

where: SR: Standardized residuals; $\bar{x}$ : Mean of residuals; $s$ : Standard deviation of residuals.

Three models were constructed which were $\mathrm{P}(26-50 \%$ ALT Inquisition Rate), $\mathrm{P}(51-75 \%$ ALT Inquisition Rate) and $\mathrm{P}(76-100 \%$ ALT Inquisition Rate) relative to $\mathrm{P}(0-25 \%$ ALT Inquisition Rate) by using multinomial logistic regression function. The models are presented on Tables 4, 5 and 6. It should be noted that the p-values of the Wald test statistics in these three tables. The probability that a particular Wald test statistic is as extreme as, or more so, than what has been observed under the null hypothesis is defined by the p-value. In multinomial logistic regression, the interpretation of a parameter estimate's significance is limited to the model in which the parameter estimate was calculated (IDRE 2014). Moreover, the odd ratios for the predictors are the exponentiation of the coefficients. The odds ratio of a coefficient indicates how the risk of the outcome falling in the comparison group compared to the risk of the outcome falling in the referent group changes with the variable in question. An odds ratio greater than one indicates that the risk of the outcome falling in the comparison group relative to the risk of the outcome falling in the referent group increases as the variable increases. In other words, the comparison outcome is more likely. An odds ratio smaller than one indicates that the risk of the outcome falling in the comparison group relative to the risk of the outcome falling in the referent group decreases as the variable increases. For a given predictor with a level of $95 \%$ confidence, it can be said that there is $95 \%$ confidence that the "true" population multinomial odds ratio lies between the lower and upper limit of the interval for outcome relative to the referent group. An advantage of a 
CI is that it is illustrative; it provides a range where the "true" odds ratio may lie (Idre 2014). Interpretation of multinomial regression is slightly different from other regression types. Estimates of independent variables are relative to the reference category like the dependent variable. In SPSS, reference category for independent variables is last category for each independent variable. Table 5 is the model for $\mathrm{P}(26-50 \%$ ALT Inquisition Rate) with respect to $\mathrm{P}(0-25 \%$ ALT Inquisition Rate).The table lists the significant factors which cause higher inquisition rates. According to the first model, it was more likely that companies dealing with electric works will face more inquisitions compared to other works. Similarly, software usage, quality control system and restricted procedure with prequalification will reduce ALT inquisition rates.

Table 6 is the model for $\mathrm{P}(51-75 \%$ ALT Inquisition Rate) with respect to $\mathrm{P}(0-25 \%$ ALT Inquisition Rate). It can be understood from odds ratios of second model that miscalculation of bid price will lead to higher ALT inquisition rates. On the contrary, asking work experience documents, quality control system and restricted procedure with prequalification will reduce ALT inquisition rates.

Table 5. Parameter estimates of 26-50\% ALT inquisition rate

\begin{tabular}{ccccccccc}
\hline & $\mathrm{B}$ & $\begin{array}{c}\text { Std. } \\
\text { Error }\end{array}$ & Wald & $\mathrm{df}$ & $\mathrm{P}$ & $\operatorname{Exp}(\mathrm{B})$ & \multicolumn{2}{c}{ 95\% Confidence Interval for Exp(B) } \\
\cline { 8 - 9 } & & & & & & Lower Bound & Upper Bound \\
\hline Intercept & -5.434 & 1.556 & 12.197 & 1 & 0.000 & & & \\
\hline $\mathrm{X} 1$ & 2.784 & 1.088 & 6.552 & 1 & 0.010 & 16.179 & 1.920 & 136.346 \\
\hline $\mathrm{X} 2$ & -2.210 & 0.545 & 16.459 & 1 & 0.000 & 0.110 & 0.038 & 0.319 \\
\hline $\mathrm{X} 3$ & 1.836 & 0.837 & 4.816 & 1 & 0.028 & 6.271 & 1.217 & 32.314 \\
\hline $\mathrm{X} 4$ & 2.679 & 0.757 & 12.518 & 1 & 0.000 & 14.570 & 3.303 & 64.267 \\
\hline
\end{tabular}

Where: B - Estimated multinomial logistic regression coefficients; Std. Error - Standard errors of the individual regression coefficients for the two respective models estimated; Wald - Wald chi-square test that tests the null hypothesis that the estimate equals 0 ; $\mathrm{df}$ - The degrees of freedom for each of the variables included in the model; $\mathrm{p}$ - The p-values of the coefficients or the probability that, within a given model, the null hypothesis that a particular predictor's regression coefficient is zero given that the rest of the predictors are in the model; $\operatorname{Exp}(\mathrm{B})$ - The odds ratios for the predictors; $95 \%$ Confidence Interval for $\operatorname{Exp}(\mathrm{B})$ : This is the Confidence Interval (CI) for an individual multinomial odds ratio given the other predictors are in the model relative to the referent group; X1- Electric works; X2 - Software usage; X3 - Quality control; X4 - Restricted procedure with prequalification.

Table 6. Parameter estimates of 51-75\% ALT inquisition rate

\begin{tabular}{ccccccccc}
\hline & $\mathrm{B}$ & $\begin{array}{c}\text { Std. } \\
\text { Error }\end{array}$ & Wald & $\mathrm{df}$ & $\mathrm{P}$ & $\operatorname{Exp}(\mathrm{B})$ & \multicolumn{2}{c}{ 95\% Confidence Interval for Exp(B) } \\
\cline { 7 - 9 } & & & & & & Lower Bound & Upper Bound \\
\hline Intercept & -9.493 & 1.910 & 24.693 & 1 & 0.000 & & & \\
\hline $\mathrm{X} 1$ & 1.590 & 0.544 & 8.557 & 1 & 0.003 & 4.905 & 1.690 & 14.237 \\
\hline $\mathrm{X} 2$ & 1.437 & 0.626 & 5.272 & 1 & 0.022 & 4.208 & 1.234 & 14.349 \\
\hline $\mathrm{X} 3$ & 1.439 & 0.714 & 4.057 & 1 & 0.044 & 4.217 & 1.040 & 17.105 \\
\hline $\mathrm{X} 4$ & 3.731 & 1.081 & 11.921 & 1 & 0.001 & 41.729 & 5.018 & 346.977 \\
\hline
\end{tabular}

Where: X1: Miscalculation of bid price; X2: Asking work experience document; X3: Quality control; $\mathrm{X} 4$ : Restricted procedure with prequalification. 
Table 7. Parameter estimates of $76-100 \%$ ALT inquisition rate

\begin{tabular}{|c|c|c|c|c|c|c|c|c|}
\hline & \multirow{2}{*}{$\mathrm{B}$} & \multirow{2}{*}{$\begin{array}{l}\text { Std. } \\
\text { Error }\end{array}$} & \multirow{2}{*}{ Wald } & \multirow{2}{*}{$\mathrm{df}$} & \multirow{2}{*}{$\mathrm{P}$} & \multirow{2}{*}{$\operatorname{Exp}(B)$} & \multicolumn{2}{|c|}{ 95\% Confidence Interval for $\operatorname{Exp}(B)$} \\
\hline & & & & & & & Lower Bound & Upper Bound \\
\hline Intercept & -5.208 & 1.454 & 12.826 & 1 & 0.000 & & & \\
\hline $\mathrm{X} 1$ & -2.677 & 1.308 & 4.188 & 1 & 0.041 & 0.069 & 0.005 & 0.893 \\
\hline $\mathrm{X} 2$ & 1.442 & 0.615 & 5.503 & 1 & 0.019 & 4.229 & 1.268 & 14.108 \\
\hline $\mathrm{X} 3$ & 1.981 & 0.812 & 5.953 & 1 & 0.015 & 7.252 & 1.477 & 35.621 \\
\hline $\mathrm{X} 4$ & -1.763 & 0.570 & 9.581 & 1 & 0.002 & 0.171 & 0.056 & 0.524 \\
\hline $\mathrm{X} 5$ & -2.603 & 1.159 & 5.047 & 1 & 0.025 & 0.074 & 0.008 & 0.717 \\
\hline $\mathrm{X} 6$ & 2.213 & 0.669 & 10.942 & 1 & 0.001 & 9.144 & 2.464 & 33.932 \\
\hline
\end{tabular}

Where: X1- Regular payment of contracting authority; X2 - Miscalculation of bid price; X3 - Asking work experience document; X4 - Software usage; X5 - Quality control; X6 - Restricted procedure with prequalification.

Last model (Table 7) stated that regular payment of contracting authority will significantly reduce ALT inquisition rates. The factors in Table 5 are also significant at this level. Software usage also is significant at this level similarly as Table 4.

\section{Conclusions}

Abnormally low tenders are one the most serious problems in procurement systems. Both researchers and construction industry search on the matter of solving this problem. In this paper, a questionnaire was prepared and collected data was analysed to capture reasons and possible solution to ALTs. To fit this purpose, three models were constructed which were $\mathrm{P}(26-50 \%$ ALT Inquisition Rate), $\mathrm{P}(51-75 \%$ ALT Inquisition Rate), P(76-100\% ALT Inquisition Rate) relative to $\mathrm{P}(0-25 \%$ ALT Inquisition Rate) by using multinomial logistic regression function.

According to ALT questionnaire, prices of work items in a tender are determined by market research at most. Also a positive weak association was found between ambiguity in tender document and cost analysis of similar works. If contracting authority also prepares conceptual cost by market research, difference between conceptual cost and bid price of contractor decreases. Decrease in this difference provides ALT to decrease. Moreover, decrease in difference between conceptual cost and tender price is the one of the aims of e-procurement. Large ratio of $0-25 \%$ ALTinquisition rate emphasizes that, prices of work items have to be found by market research.

The significant factors for different inquisition rates were captures by the statistical analysis. For all three rates, quality control and restricted procedure with prequalification were found to be significant. It was found out from questionnaire that proper and sufficient quality control is not applied in construction period. It was determined from statistical tests that adequate and proper quality control reduces ALT Inquisition rate. This shows that contractors should adopt an effective quality control system to reduce ALT inquisition. Moreover, in tendering, restricted procedure with prequalification will reduce ALT problems. Electrical works need special attention during tendering process. For higher 
inquisition rates asking work experience document is significant. This shows that doing similar jobs in the past will reduce ALT inquisition. Also regular payment of contracting authority will lead to less inquisition rates.

Questionnaire results and statistical tests reveal that computer software users generally do not face with ALT inquisition. Use of softwares with proper quantity take-off provides determining of bid price properly. Therefore, use of software computer software will decrease ALT ratio if it is used with experienced staff.

This paper listed a multinomial logistic regression model on 430 company data to develop strategies to reduce ALT inquisition rates.

\section{References}

Agresti, A. 2002. Categorical data analysis. New York: Wiley-Interscience. ISBN 0-471-36093-7

Alexandersson, G.; Hultén, S. 2006. Predatory bidding in competitive tenders: a Swedish case study, European Journal of Law and Economics 22(1): 73-94. http://dx.doi.org/10.1007/s10657-006-8981-7

Ballesteros-Pérez, P.; González-Cruz, M. C.; Cañavate-Grimal, A.; Pellicer, E. 2013. Detecting abnormal and collusive bids in capped tendering, Automation in Construction 31: 215-229.

http://dx.doi.org/10.1016/j.autcon.2012.11.036

Banaitiene, N.; Banaitis, A. 2006. Analysis of criteria for contractors' qualification evaluation, Technological and Economic Development of Economy 12(4): 276-282.

http://dx.doi.org/10.1080/13928619.2006.9637754

Bergman, M. A.; Lundberg, S. 2013. Tender evaluation and supplier selection methods in public procurement, Journal of Purchasing \& Supply Management 19: 73-83.

http://dx.doi.org/10.1016/j.pursup.2013.02.003

Calveras, A.; Ganuza, J. J.; Hauk, E. 2003. Wild bids, gambling for resurrection in procurement contracts, Journal of Regulatory Economics 26(1): 41-68. http://dx.doi.org/10.1023/B:REGE.0000028013.76488.44

Conti, P. L.; Naldi, M. 2008. Detection of anomalous bids in procurement auctions, Decision Support Systems 46(1): 420-428. http://dx.doi.org/10.1016/j.dss.2008.08.002

Conti, P. L.; De Giovanni, L.; Naldi, M. A. 2012. Rank-and-compare algorithm to detect abnormally low bids in procurement auctions, Electronic Commerce Research and Applications 11(2): 192-203. http://dx.doi.org/10.1016/j.elerap.2011.12.008

Coskun, H.; Erdis, E.; Demirci, M. 2013. Pricing policies as a marketing strategy in the construction industry: case study of Turkish companies, Technological and Economic Development of Economy 19(sup1): S1-S21. http://dx.doi.org/10.3846/20294913.2013.821688

Directive 2004/18/EC of the European Parliament and of the Council. 2004. Coordination of procedures for the award of public works contracts, public supply contracts and public service contracts.

Drew, D. S.; Skitmore, R. M. 1997. The effect of contract type and size on competitiveness in bidding, Construction Management and Economics 15: 469-489. http://dx.doi.org/10.1080/014461997372836

Garson, D. G. 2014. Logistic regression [online], [cited 28 January 2014]. Available from Internet: http:// www2.chass.ncsu.edu/garson/PA765/logistic.htm

Gokce, H. 2004. Evaluation of Turkish public procurement system appliance for a year, I, International Transparency and Efficiency in Public Procurement Symposium, 12 December 2004, Istanbul, Turkey. Istanbul: Ozgun Press, 96-99.

Harrower, J. R. 1999. Prevention, detection and elimination of abnormally low tenders in the European construction industry. DG III Working Group on Abnormally Low Tenders Report. 
Hartono, B.; Yap, C. M. 2011. Understanding risky bidding: a prospect-contingent perspective, Construction Management and Economics 29: 579-593. http://dx.doi.org/10.1080/01446193.2011.569733

IDRE. 2014. Annotated SPSS output, multinomial logistic regression [online], [cited 01 February 2014]. Available from Internet: http://www.ats.ucla.edu/stat/spss/output/mlogit.htm

Ioannou P. G.; Awwad, R. E. 2010. Below-average bidding method, Journal of Construction Engineering and Management 136(9): 936-946. http://dx.doi.org/10.1061/(ASCE)CO.1943-7862.0000202

Jun, C. 2013. Analysis of evaluating bid price of reasonable lowest price in construction project bidding, Advanced Materials Research 709: 775-779.

http://dx.doi.org/10.4028/www.scientific.net/AMR.709.775

Klemperer, P. 2002. What really matters in auction design, Journal of Economic Perspectives 16: 169-190. http://dx.doi.org/10.1257/0895330027166

Laryea, S.; Hughes, W. 2011. Risk and price in the bidding process of contractors, Journal of Construction Engineering and Management 137: 248-259. http://dx.doi.org/10.1061/(ASCE)CO.1943-7862.0000293

Lo, W.; Lin, C. L.; Yan, M. R. 2007. Contractor's opportunistic bidding behaviour and equilibrium price level in the construction market, ASCE Journal of Construction Engineering and Management 133(6): 409-416. http://dx.doi.org/10.1061/(ASCE)07339364(2007)133:6(409)

Lo, W.; Yan, M.-R. 2009. Evaluating qualification-based selection system: a simulation approach, Journal of Construction Engineering and Management 135(6): 458-465. http://dx.doi.org/10.1061/(ASCE)CO.1943-7862.0000013

Skitmore, R. M. 2002. Identifying non-competitive bids in construction contract auctions, Omega 6: 443-449. http://dx.doi.org/10.1016/S0305-0483(02)00057-9

Skitmore, R. M.; Lo, H. P. 2002. A method for identifying high outliers in construction contract auctions, Engineering, Construction and Architectural Management 9: 90-130.

http://dx.doi.org/10.1046/j.1365-232x.2002.00241.x

Turskis, Z. 2008. Multi-attribute contractors ranking method by applying ordering of feasible alternatives of solutions in terms of preferability technique, Technological and Economic Development of Economy 14(2): 224-239. http://dx.doi.org/10.3846/1392-8619.2008.14.224-239

Unuvar, R. 2004. Role, importance and function of public procurement authority in the sector of public procurement in Turkey, I, International Transparency and Efficiency in Public Procurement Symposium, 12 December 2004, İstanbul, Turkey. İstanbul: Ozgun Press, 186-189.

Watt, D. J.; Kayis, B.; Willey, K. 2009. Identifying key factors in the evaluation of tenders for projects and services, International Journal of Project Management 27: 250-260.

http://dx.doi.org/10.1016/j.ijproman.2008.03.002

Yu, W.-D.; Wang, K.-W. 2012. Best value or lowest bid? A quantitative perspective, Journal of Construction Engineering and Management 138(1): 128-134.

http://dx.doi.org/10.1061/(ASCE)CO.1943-7862.0000414

Murat GUNDUZ is a professor of Civil Engineering Department at Qatar University. He completed a Master's degree in Construction Engineering and Management at Georgia Institute of Technology USA in 1998. He completed his PhD in the same area at the University of Wisconsin, Madison USA in 2002. His research interest is construction engineering and management. He is an editorial board member of ASCE Journal of Management in Engineering.

H. Volkan KARACAN works at GENA Construction Limited as a civil engineer. 